\title{
ГОСУДАРСТВЕННО-КАПИТАЛИСТИЧЕСКИЙ И КООПЕРАТИВНЫЙ ПУТИ ПЕРЕХОДА К КОММУНИЗМУ И ПАРТИЙНАЯ ПРОГРАММА
}

\author{
(c) 2020 Будович Юлия Ивановна \\ доктор экономических наук, доцент, профессор Департамента экономической теории \\ Финансовый университет при Правительстве Российской Федерации, Россия, Москва \\ E-mail: JBudovich@fa.ru \\ ORCID: https://orcid.org/0000-0001-8691-947X
}

\section{(c) 2020 Будович Маргарита Сергеевна}

кандидат экономических наук, доцент Департамента экономической теории Финансовый университет при Правительстве Российской Федерации, Россия, Москва

E-mail:MSBudovich@fa.ru

ORCID: https://orcid.org/0000-0002-7234-1408

В настоящей статье с точки зрения теории нефинансовой экономики обосновывается более высокая, по сравнению с акционерным обществом, эффективность таких форм предприятия, как централизованно управляемое государственное предприятие и производственный кооператив, а также более высокая эффективность последнего по сравнению с государственным предприятием, соответственно, обосновывается большая приемлемость кооперативного пути перехода к коммунизму в марксисткой теории. В статье доказывается, что основоположники марксизма включили в «Манифест коммунистической партии» (1848) положение о государственно-капиталистическом, а не о кооперативном, пути перехода к коммунизму, исходя не из экономических, а политических соображений, так как надеялись лично возглавить революционную партию, победоносную пролетарскую революцию, а также весь дальнейший процесс уничтожения «старого мира».

Ключевые слова: коммунизм, государственное предприятие, производственный кооператив, нефинансовая экономика.

Марксистская экономическая теория, в частности теория перехода от капитализма к коммунизму, во многом созвучна с теорией нефинансовой экономики, поскольку в первой, так или иначе, язвы капитализма выводились из развития финансовых отношений, а переход к коммунизму связывался со сворачиванием финансовых отношений.

Теория нефинансовой экономики (экономики без финансов) исходит из того что у всех финансовых, т.е. основанных на трансфертных сделках, систем ресурсообеспечения (кредитных, пенсионных, налоговых, страховых и т.д.) [12, с. 46] имеются нефинансовые, т.е. основанные на сделках купли-продажи товаров, заменители, например у налогов как источника финансирования исследований и разработок (ИиР) есть такой нефинансовый заменитель, как выручка компаний от реализации товаров. Теория нефинансовой экономики, в отличие от марксистской теории, рассматривает социальноэкономическое развитие через призму борь- бы не классов, а альтернативных финансовых и нефинансовых систем ресурсообеспечения («финансов» и «нефинансов»). При этом она отмечает наличие в мире в целом тенденции вытеснения финансов нефинансами, например выручка фирм от реализации товаров вытесняет налоги как источник финансирования ИиР, госзакупки ИиР - субсидии из госбюджета на выполнение ИиР как источник непосредственного обеспечения ИиР [3, с. 73-74, 87-88]. Это объясняется большей эффективностью (доступностью, экономичностью и безопасностью) нефинансов по сравнению с финансами, как для получателей ресурсов, так и для ресурсодателей. Например, выход результатов интеллектуальной деятельности (РИД) на рубль средств, затраченных на ИиР из выручки фирм, выше, чем на рубль таковых из полученных государством налогов, о чем говорит, в частности, крайне низкая эффективность государственных расходов на ИиР в нашей стране [2, с. 11]. В свою очередь, большая эффективность нефинансов по сравнению с финанса- 
ми объясняется платным (оплаченным реальными активами) или бесплатным получением соответствующих ресурсов и доходов, например больший выход РИД на рубль выручки фирм по сравнению с рублем налогов - платным (в обмен на товары) получением выручки фирмами и бесплатным получением налогов государством.

Теория нефинансовой экономики также отмечает, что вытеснение финансов нефинансами зачастую происходит при активном государственном участии, но господдержка нефинансовых систем является непоследовательной, вследствие чего процесс вытеснения финансов нефинансами носит нелинейный характер (так, нефинансовые альтернативы решения каких-то проблем могут отступить или даже исчезнуть, что вызывает потери благосостояния). Это объясняется активной внеэкономической борьбой, которую ведут финансы с нефинансами, прежде всего посредством законодательства, регулирующего деятельность нефинансовых систем обеспечения.

Одной из систем обеспечения социальноэкономического развития является система «капитал», или система наделения предприятия собственными средствами при его учреждении или расширении. В ней также представлены финансовые (трансфертные) и нефинансовые (товарообменные) разновидности. Для первых характерно то, что учредители в обмен на взносы в капитал предприятия получают в собственность свидетельства о взносах, например акции (фиктивный капитал), а для вторых - то, что учредители взамен таких же взносов получают в собственность их товарный эквивалент, а именно имущество предприятия (физический капитал), которым владеют на праве общей собственности. Разница объясняется тем, что в первом случае учредители не собираются заниматься непосредственным управлением предприятием, дающим экономическое (реальное) право собственности (т.е. право делать с вещью все, что угодно) на его имущество, а во втором - собираются. Капитальная система классического акционерного общества (AO), т.е. АО, управляемого наемными топ-менеджерами, является финансовой, централизованно управляемого государственного предприятия - нефинансовой, так как государство-учредитель непосредственно ведет все дела предприятия (устанавливает все плановые показатели деятельности госпредприятия и строго следит за их исполнением, обеспечивает его заказами, централизованным кадровым, материальным, научным и пр. снабжением), классического производственного кооператива (ПК) - также нефинансовой, так как его пайщики намерены сами непосредственно управлять соответствующим предприятием. При этом (экономическими) собственниками имущества АО становятся наемные топ-менеджеры, а имущества централизованно управляемого госпредприятия и ПК - учредители соответствующих предприятий.

Централизованно управляемое госпредприятие и ПК (финансовые по способу наделения собственными средствами формы хозяйствования) являются более эффективными формами хозяйствования, чем АО (нефинансовая по данному критерию форма хозяйствования). Это объясняется платным и бесплатным получением в собственность имущества предприятия его топ-менеджерами. Государство-топ-менеджер и учредители ПК-топ-менеджеры платят за полученное ими в собственность имущество предприятия его полную реальную стоимость, в связи с чем оно приобретает в их глазах адекватную ценность, из-за чего они проявляют адекватную заботу о его количественном и качественно росте (именно в этом проявляется забота от растущем имуществе, например о животном или растении, к которому относится и имущество предприятия), проявляющуюся в самом высоком качестве управления предприятием, чертами которого являются: предпочтение долгосрочной прибыли краткосрочной, предпочтение производственного развития предприятия его социальному развитию, ответственное отношение к обязанностям по управлению, неприятие воровства имущества предприятия. Наемные же топ-менеджеры АО не платят за полученное ими в собственность имущество АО ничего, в связи с чем оно получает в их глазах ценность значительно ниже адекватной, из-за чего они проявляют недолжную заботу о его количественном и качественном росте, что находит проявление в низком качестве управления предприятием, чертами которого являются: предпочтение краткосрочной прибыли, предпочтение социального развития предприятия, халатное отношение к обязанностям по управлению и воровство имущества предприятия.

Заметим, что низкое качество управления AO, ставшим к середине XIX в. основной формой крупного хозяйствования в промышленно- 
сти, на транспорте и др., прежде всего, в Великобритании, отмечали сами основоположники марксизма К.Маркс и Ф.Энгельс. Еще в 1847 г. Ф. Энгельс в «Принципах коммунизма» выделил в крупной промышленности такие проявления самой опасной «болезни» управления предприятиями - погони за краткосрочной прибылью, как понижение зарплаты рабочим до уровня прожиточного минимума и планирование выпуска не от общественных потребностей, а исходя из величины доступного капитала (свободная конкуренция), объясняя ими невыносимое положение наемных работников, чреватое революциями, регулярные экономические кризисы, вызывающие банкротство фабрикантов и ввергающие рабочих в нищету, что ставит общество на грань революции [15, с. 328-329]. Фактически в связи с низким качеством управления AO основоположниками марксизма и ставился вопрос об уничтожении частной собственности на средства производства и замене ее другими формами собственности (хозяйствования), характеризующимися, таким образом, более высоким качеством управления, в частностью способностью к обеспечению планомерного развития народного хозяйства.

С точки зрения теории нефинансовой экономики такая нефинансовая форма предприятия, как ПК, является более эффективной, чем такая нефинансовая форма предприятия, как централизованно управляемое госпредприятие. Это объясняется платным и бесплатным получением в собственность имущества уже лицами, непосредственно управляющими элементами предприятия разного уровня вплоть до рабочих мест. Дело в том, что учреждение классического ПК предполагает превращение учредителей в трудовой коллектив предприятия, т.е. учредители работают не только топ-менеджерами, но и исполняют все нижестоящие должности, что и превращает их в лиц, непосредственно управляющих элементами предприятия вплоть до рабочих мест, т.е. в экономических собственников соответствующих частей его имущества. При этом данное имущество является сполна оплаченным ими реальными средствами, что и побуждает проявлять должную заботу о нем, выражающуюся в самом высоком качестве управления этим имуществом. Известно, что наличие у работников (оплаченной реальными средствами) собственности на средства производства и продукты труда придает им дополнительный сти- мул к производительному труду и бережливому отношению к соответствующему имуществу. В результате того, что топ-менеджерам ПК не нужно противостоять оппортунизму нижестоящих работников, что имеет место на госпредприятии, работники которого не платили за экономическую собственность на управляемое ими имущество предприятия, ПК функционируют более эффективно, чем централизованно управляемые госпредприятия, и ПК является более эффективной нефинансовой формой хозяйствования, чем соответствующее госпредприятие.

Заметим, что в случае централизованно управляемого госпредприятия формальные топ-менеджеры (генеральный директор, финансовый директор и т.д.) фактически таковыми не являются, реально выступая верхушкой менеджеров среднего звена, поскольку фактический топ-менеджмент здесь представляет государство. При этом они превращаются в реальных топ-менеджеров в случае, если госпредприятию предоставляется хозяйственная самостоятельность, т.е. непосредственное управление делами предприятия переходит к ним. В этом случае госпредприятие из эффективной формы хозяйствования превращается в неэффективную, так как его топ-менеджеры, как лица, не платившие за право экономической собственности на имущество предприятия и, следовательно, недостаточно его ценящие, не способны обеспечить высокое качество управления им. Понятно, что в этом случае капитальная система госпредприятия превращается в финансовую, поскольку государство, отказавшись от непосредственного управления предприятием, перестает быть собственником его имущества, становясь собственником его фиктивного капитала. Именно предоставлением госпредприятиям все большей и большей хозяйственной самостоятельности на протяжении десятков лет с середины 1950-х гг. и объясняется в теории нефинансовой экономики последовательное замедление экономики СССР, вызвавшее в итоге распад страны [11, с. 255-256].

Положение о большей эффективности кооператива, чем централизованно управляемого государственного предприятия, обусловленной переходом средств производства в собственность простых работников, подтверждают данные о росте эффективности производства на казенных заводах военного ведомства Российской Империи, захваченных рабочими после Февральской революции 1917 г. под влиянием 
агитации, развернутой анархистами. Заметим, что наиболее громким событием самозахвата стала экспроприация Шлиссельбургских пороховых заводов и сельхозугодий под руководством анархиста Жука, а в преддверии и после Октябрьской революции 1917 г. самозахваты предприятий рабочими приобрели массовый характер (в Петрограде - особенно в Нарвском и Московском районах). Превращение предприятий, как государственных, так и частных, в «фабричные коммуны», сразу же начавшие объединяться в союзы, и было содержанием известного «рабочего контроля», направляемого фабричнозаводскими комитетами (фабзавкомами) предприятий. Известно, что на Патронном заводе, даже после удаления всей администрации и введения 8-часового рабочего дня, продуктивность снизилась всего на 2\%, на Пороховом заводе, где была удалена почти вся администрация, количество брака снизилось с 30\% до 15, на Орудийном и Оптическом заводах производительность выросла на 28 и 11\% соответственно, на Сестрорецком заводе выпуск винтовок и взрывателей вырос с 450 и до 600, а взрывателей - с 4500 до 6000 штук в день соответственно, на Охтинском заводе выпуск пороха вырос с 800 до 900 пудов в сутки, а брак снизился с 35 до 15\% [21].

Конечно же, рабочие не платили за свою долю в имуществе предприятий, однако стать эффективными собственниками средств производства им позволила убежденность в том, что имущество предприятий есть недоплаченная рабочим заработная плата. Это положение внедрялось в сознание рабочих не только по анархистскому («собственность - это кража»), но и по марксистскому («экспроприация экспроприаторов», а по-русски - «грабь награбленное») каналам. Теория неоплаченного труда, разработанная Р. Оуэном, была подхвачена как философом анархизма П.Ж.Прудоном, так и К.Маркcom [19].

В связи с тем, что производственный кооператив, в силу высокого качества управления им склонный к объединению в союзы кооперативов разного уровня в целях обеспечения планомерности их функционирования в масштабах страны, является более эффективной формой хозяйствования, чем централизованно управляемое государственное предприятие, то, с точки зрения теории нефинансовой экономики, и кооперативный (т.е. на основе кооперативов, ассоциированных в союзы разного уровня) путь перехода к коммунизму является более приемлемым, прежде всего более быстрым, чем государственно-капиталистический (т.е. на основе государственных предприятий с административно-командной системой управления ими) путь.

Однако, как известно, в программном документе коммунистической партии, а именно в «Манифесте коммунистической партии» (1848), написанном К.Марксом и Ф.Энгельсом по поручению Союза коммунистов в преддверии европейских революций 1848-1849 гг., в качестве пути перехода к коммунизму фигурирует менее эффективный, государственнокапиталистический путь - в Манифесте зафиксировано требование шаг за шагом вырвать у буржуазии весь капитал, централизуя его в руках государства, т.е. пролетариата, организованного в господствующий класс [15, с. 446].

При этом, как показывает исследование, основоположники марксизма не только были прекрасно осведомлены об альтернативном, кооперативном пути перехода к коммунизму, но и, вплоть до написания ими Манифеста, пропагандировали его.

Прежде всего, заметим, что страны, в которых основоположники марксизма проживали в то время, когда стали активно увлекаться политической экономией, были странами-лидерами кооперативного развития, причем оно к середине XIX в. претерпевало расцвет. При этом претерпевали расцвет все виды кооперативов (потребительские, кредитные и т.д.), в том числе и производственные кооперативы (ПК). Это такие страны, как Англия и Франция.

Ф.Энгельс почти два года прожил в Англии (в 1842-1844 гг.), куда был направлен для завершения коммерческого образования на хлопкопрядильной фабрике своего отца в Манчестере. Здесь он познакомился с повседневным бытом рабочего класса, основательно узнал английскую жизнь, нравы и мировоззрение, вступил в контакты с немецкой революционной рабочей организацией «Союз справедливых», английскими чартистами, писал статьи в их газеты [23]. И именно Великобритания в те времена характеризовалась значительным развитием ПК. Отдельные попытки производственной кооперации в виде коллективных мельниц и объединений ткачей-ремесленников в Англии и Шотландии относятся еще к 1760-м гг. [16], например в 1769 г. возник кооператив ткачей. В 1777 г. 
появился кооператив портных [17]. В период промышленного переворота ПК создавали разорившиеся ремесленники и потерявшие работу квалицированные рабочие, чтобы, пользуясь ростом производительности, которую дает разделение труда, конкурировать с дешевыми фабричными товарами [16]. Уже к 1832 г. в Англии и Шотландии было 500 рабочих ПК [17].

К.Маркс с конца октября 1843 г. до начала февраля 1845 г. проживает в Париже, где не только знакомится с Ф.Энгельсом, обратившим его внимание на положение рабочего класса, но и завязывает широкие знакомства с представителями революционных кругов Франции и других стран, живущими в Париже (в частности с П.Ж.Прудоном и М.А.Бакуниным), вступает в непосредственные контакты с рабочими организациями как французов, так и немецких эмигрантов, выпускает журнал [14]. И именно во Франции впервые ПК возникли как научно организованная форма хозяйствования (в 1830-е гг.), основываясь на идеях Шарля Фурье, Луи Блана и Филиппа Бюше, которые определили принципы их формирования, проведя, в частности, необходимые эксперименты. Первый из них возник около 1832 г. при помощи Ф.Бюше, к которому явились несколько подмастерий-столяров, пожелавших начать освобождение рабочего класса посредством ассоциации [16]. В 1834 г. возник кооператив рабочих-ювелиров, в 1835 - каменотесов [17].

К. Маркс не только мог знать об успехах ПК, но и в соответствующий период жизни в Париже (в 1843-1845 гг.) ознакомился с трудами французских экономистов, предлагавших кооперативный путь перехода к коммунизму, прежде всего мирный. Известно, что в Париже К. Маркс читал П.Прудона, Л.Блана, Э.Кабе, Ш.Фурье, К.А. Сен-Симона [18]. В частности, проект Л. Блана предусматривал создание общественных мастерских, управляемых самими рабочими, государством на средства специального займа. Эти трудовые ассоциации при поддержке государства должны были постепенно вытеснить частные предприятия, а затем, объединившись в отраслевые союзы, начать успешную борьбу с промышленными кризисами. В преддверии же революций 1848-1849 гг. Л.Блан опубликовал политическую программу партии «Реформа», в которой уже содержалось требование перехода к ассоциации производственных кооперативов на основе «верховенства народа», или демократи- ческой республики [6]. Интересно, что автор из вышеуказанного ряда Этьен Кабе в изданном в 1840 г. «Путешествии в Икарию», представляющим собой фантастические путевые записки английского лорда-путешественника, фактически предложил государственно-капиталистический путь перехода к коммунизму через революцию. Икарийцы, недовольные социальным строем, осуществили у себя государственный переворот, выбрав для проведения в течение пятидесяти лет коммунистического идеала диктатором Икара. В момент прибытия лорда Керисдаля в Икарию территория страны вместе с постройками принадлежала уже всей нации. Всё имущество нации, включая произведения промышленности и земледелия, было одним капиталом, которым народ, через своих избранников, распоряжался как своей нераздельной собственностью [7]. Интересно, что К. Маркс не только читал труды вышеуказанных авторов, но и восхищался ими, например, трудами П.Прудона [18], выступившего философом коммун.

В работе «Описание возникших в новейшее время и еще существующих коммунистических колоний» (1844) на основе опубликованных свидетельств путешественников Ф.Энгельс доказывает сомневающимся, что социализм или коммунизм, т.е. общественная жизнь и деятельность на основе общности имущества, не только возможен, но и уже давно осуществляется во многих общинах в Америке и в одной местности в Англии, да еще и с полным успехом (за последние 10-15 лет все коммунистические колонии так разбогатели, что они имеют все, чего можно желать, еще и в большем количестве).

Общность имущества, или такая разновидность ПК, как производственно-потребительская коммуна, основана на следующих принципах (из договора раппистов): каждый вносит в общину все, что имеет, в общине все равны, законы и правила общины одинаково обязательны для всех, все трудятся только на благо всей общины, а не каждый для одного себя, община обязуется снабжать каждого члена и его семью всем необходимым для жизни и обеспечивать необходимый уход во время болезни и в старости.

Ф. Энгельс рисует идеальную картину экономической и прочей жизни общин. Вот описание общин шейкеров в Америке: каждая из них с населением 300-800 чел.- красивый и правильно распланированный город с жилыми домами, фабриками, мастерскими, зданиями для собраний, 
амбарами, имеющимися в изобилии цветниками, огородами, садами, виноградниками. Есть, луга и пахотная земля, всякого рода скот: лошади, коровы, овцы, свиньи и т.д. причем больше, чем может требоваться и самых лучших пород. Амбары всегда полны зерна, а кладовые - ткани для одежды. Как отмечает Ф. Энгельс, посетивший их английский путешественник сказал, что не понимает, зачем эти люди, у которых всего в избытке, работают, по-видимому - исключительно ради времяпрепровождения. Нет приютов для бедных и богаделен, ибо нет ни одного бедняка и нуждающегося. Нет полицейских, судей, адвокатов и солдат, нет тюрем и исправительных домов, но все идет своим чередом.

Вот как работает система распределения (у раппистов): все необходимое семьи получают с общественных складов, бесплатно и сколько пожелают, одежда или обувь изготовляются специальными портными и сапожниками по их вкусу, мясо и другие пищевые продукты выдаются каждой семье по числу членов, у них всего вдоволь и в избытке.

Общины характеризуются и передовой техникой. Другой путешественник тщательно обследовал мастерские, фабрики, кожевенные заводы, лесопильни и т.д. одного из городов и нашел все заведение совершенным.

Живущие в общинах люди абсолютно счастливы. Так, все жители одного из городов прекрасно одеты, хорошо питаются, великолепно живут. Это веселые, довольные, счастливые и добродетельные люди, не знающие уже много лет никакой нужды.

Своим всесторонним процветание общины обязаны, естественно, экономичности соответствующей формы хозяйствования. Как отмечает Ф.Энгельс, при ней люди затрачивают меньше труда, отчего имеют больше свободного времени для своего духовного развития, в связи с чем они лучше и нравственнее, чем их соседи, сохранившие частную собственность.

Ф.Энгельс предсказывает бурный рост коммунистических общин. Как он отмечает, американцам надоело оставаться рабами кучки богачей, живущих их трудом, и очевидно, что общность имущества скоро будет введена в значительной части страны.

Именно объединение в коммунистические общины предлагает Ф. Энгельс наемным работникам, прежде всего бедным рабочим, которые, не имея никакой собственности, могут остаться без куска хлеба из-за непредвиденных и неизбежных случайностей, как путь к независимому, обеспеченному и свободному от забот существованию, полному равноправия с теми, кто благодаря своему богатству превращает рабочих в своих рабов. При этом он предлагает рабочим вступать в партии, добивающиеся общности имущества. Интересно, что в данной работе Ф.Энгельса и намека нет на необходимость совершения пролетарской революции для ускорения соответствующего процесса.

Общиной «в одной местности Англии» является общность имущества, созданная Робертом Оуэном [9].

В «Принципах коммунизма» (написано в конце октября - ноября 1847 г.), переработкой которых является Манифест, Энгельс пишет, что частную собственность заменит «...общее пользование всеми орудиями производства и распределение продуктов по общему соглашению, или так называемая общность имущества» $[15$, с. 330]. Соответственно, сосредоточение всего капитала, производства и обмена в руках нации после победы пролетариата [15, с. 333] является лишь промежуточной целью преобразования отношений собственности. Но, как было показано выше, в Манифесте, написанном в декабре 1847 - январе 1848 г., т.е. к написанию которого К. Маркс и Ф.Энгельс приступили менее чем через месяц после завершения Принципов, это становится уже конечным пунктом.

Лишь через десятилетия основоположники марксизма возвращаются к идее кооперативного пути перехода к коммунизму. Современный исследователь марксизма В.И.Дьяченко убедительно доказал, что «поздние» К. Маркс и Ф. Энгельс видели переход к коммунизму после завоевания пролетариатом политической власти через развитие коммун, кооперативных фабрик и рабочих кооперативов и их объединений. Так, в «Гражданской войне во Франции» (1871) К. Маркс писал, что если объединенные кооперативы организуют национальное хозяйство по общему плану, взяв тем самым на себя руководство им и прекратив анархию производства и его периодические конвульсии, то это и будет коммунизм. В письме Герману Юнгу от 14 июля 1870 г. К. Маркс указывает, что кооперативная система, ограниченная карликовыми предприятиями, которые только и могут создать рабы наемного труда, никогда не преобразует капиталистическое общество, если власть не перейдет от 
капиталистов к самим производителям. А Ф.Энгельс в письме Августу Бебелю 20-23 января 1886 г. фактически объясняет, зачем нужна такая власть. Он считает, что кооперативы должны создаваться тружениками не с нуля (с помощью государства - по Шульце-Деличу, или самостоятельно - по Лассалю), а возникать в действующем производстве, например когда рабочие на кооперативных началах запускают фабрики, брошенные хозяевами, как того требовала от них Парижская коммуна. Кроме того, при кооперативном пути перехода к коммунизму, по Ф.Энгельсу, государство первое время должно владеть средствами производства, чтобы особые интересы кооперативов не могли возобладать над интересами общества в целом [5]. Понятно, что передачу фабрик в общую собственность работников на законных основаниях и использование госсобственности для отстаивания интересов всего общества может обеспечить только власть, принадлежащая самим работникам.

Конечно же, эта трансформация взглядов объясняется и успехами самой производственной кооперации, ее распространением по всему миру. В Италии первым возник кооператив художественного стекла в 1856 г., в 1860-1870-е гг. возникли кооперативы печатников, столяров, обувщиков, ювелиров, текстильщиков, в 1884 г. по соглашению между владельцами фабрик и рабочими были созданы производственные кооперативы керамистов, машиностроителей и кожевников [16]. В Германии производственные кооперативы возникают с начала 1860-х гг.: маслодельные, сыроваренные, винодельческие и т.д. [17]. Кооперативы ремесленников появляются в Японии и Испании в 1842 г., Португалии - 1858, Сальвадоре - 1860, Сербии - 1870, Мексике - 1875, Канаде - 1876 [16]. Во время Парижской коммуны 1871 года, за которой пристально следил К.Маркс, в Париже работало 45 только крупных ПК, причем 10 из них были сформированы на базе промышленных предприятий за 72 дня Коммуны [16].

Однако, по нашему мнению, это изменение взглядов на пути перехода к коммунизму, как и предыдущая трансформация, совершившаяся после написания Принципов (см. выше), объясняется, прежде всего, изменением возможностей основоположников марксизма лично возглавить революционную партию, что позволяло, в случае победы пролетарской революции, получить неограниченную (диктаторскую) власть в стране, в частности лично возглавить весь процесс уничтожения «старого мира». Однако осуществить последнюю мечту можно лишь при условии, что средства производства (предприятия) будут «шаг за шагом» переходить в собственность государства, возглавляемого партией. Передача же предприятий в собственность их трудовым коллективам с образованием соответствующими коммунами и кооперативами негосударственных органов народнохозяйственного управления означает утрату партией экономической власти, что резко ослабляет ее возможности (и возможности ее лидеров) навязывать свою волю стране и вообее не гарантирует удержания партии у власти. Обратим внимание на то, что в Манифесте требованию централизации капитала в руках государства сопутствует намерение коммунистической партии до конца возглавлять социальную революцию. В нем отмечается, что интересы коммунистов совпадают с интересами пролетариата, тем более, что первые позиционируются как часть второго, отличающаяся четким пониманием условий, хода и результатов рабочего движения [15, с. 437], а конечной же целью пролетариата и, следовательно, коммунистов, является уничтожение классов и классовых противоположностей [15, с. 447], т.е. построение коммунизма.

Некоторые исследователи жизни и творчества К.Маркса и Ф.Энгельса считают основоположников марксизма как революционеровпрактиков неудачниками, например Ж. Аттали в книге «Карл Маркс» проводит мысль, что влияние К. Маркса на мир определялось лишь идеями, тогда как в других видах деятельности (как редактор газеты, политический организатор, отец семейства и т.д.) он не был успешным [8]. Между тем, в период, когда основоположники марксизма писали Манифест (в декабре 1847 - январе 1848 г.), революционно-партийная карьера К. Маркса (как и Ф.Энгельса) претерпевала стремительный подъем. Неудачной была лишь первая попытка К. Маркса и Ф. Энгельса проникнуть в руководство международной рабочей партии, предпринятая в самом начале их революционной деятельности (с 1846 г.), а именно деятельность по созданию таковой (на принципах научного коммунизма) в на основе коммунистических корреспондентских комитетов (ККК), организовывавшихся К.Марксом и Ф.Энгельсом в Германии, Бельгии, Франции и Англии, во главе с Брюссельским ККК, у руля которого они 
стояли [20]. Попытка сорвалась из-за недопонимания коллег по Брюссельскому ККК [10]. Но уже в августе 1847 г. К. Маркс и Ф.Энгельс создают в Брюсселе Немецкое рабочее общество (НРО) [20], а осенью того же года К. Маркс, действуя от имени НРО, объявляет о создании Брюссельской демократической ассоциации (БДА), ставшей крупным центром международного демократического движения, поддерживавшим связь с демократами Великобритании, Франции, Германии, Польши и др. При этом К. Маркс становится вице-президентом БДА [24]. И еще весной 1847 г. К. Маркса и Ф.Энгельса приглашают вступить в лондонский Союз справедливых (представлявший, главным образом, немецкое рабочее движение, однако, лежавшее в те времена в основе всего международного рабочего движения и получившее широкое распространение, прежде всего, в Германии и Швейцарии) его руководители, убедившиеся в правильности научного коммунизма (на фоне практической несостоятельности господствовавших в нем коммунистических теорий, например теории, выводившей коммунизм из раннего христианства), причем с целью возглавить реорганизацию Союза и сформировать его новую программу на соответствующих принципах. Летом 1847 г. на первом конгрессе Союз был реструктурирован (теперь он состоял из общин на низах, далее округов, руководящих округов и центрального комитета и конгресса), переименован в Союз коммунистов, в качестве цели получил свержение буржуазии и установление господства пролетариата, уничтожение старого буржуазного общества, основанного на антагонизме классов, и основание нового общества без классов и частной собственности. На втором конгрессе, состоявшемся в конце ноября - начале декабря 1847 г., новые принципы были приняты единогласно в трактовке К. Маркса, и ему и Ф.Энгельсу было поручено выработать манифест, старый лозунг «Все люди - братья» был заменен на «Пролетарии всех стран, соединяйтесь!». Очевидно, такая роль в развитии Союза позволяла рассчитывать основоположникам марксизма на самые высокие должности в его руководстве и даже на лидерство (это, возможно, заранее обговаривалось), что в итоге и произошло, так как в марте 1848 г., уже после начала февральской революции во Франции, полномочия ЦК были переданы К.Марксу с поручением создать новый ЦК в Париже, который он, судя по первой подписи под «Требованиями коммунистической партии в Германии» [22], и возглавил. К сожалению для К. Маркса и Ф.Энгельса, Союз коммунистов оказался весьма слабой организацией для того, чтобы обеспечить победу европейских революций. Таким образом, пункт о централизации собственности в руках государства основоположники марксизма вполне могли включить в программу коммунистической партии «под себя».

О желании К. Маркса лично поучаствовать не только в крушении, но и в полном разрушении старого мира, лучше всего говорит его юношеское стихотворение «Человеческая гордость»: «С презреньем, закованной в латы рукою, Я врежу миру в лицо, И увижу крушение этого гигантского карлика, Чьё падение не угасит моего пыла. Богоподобный, я смогу ходить, Победоносно по руинам разрушенного Царства. Каждое моё слово - пекло и раздор, И почувствую себя равным Создателю» [4, с. 29-30].

По мнению Е. Майбурда, порыв к личной диктаторской власти не покидал К. Маркса и после неудачных революций 1848-1849 гг. При этом К.Маркс уже не собирался лично вести людей на баррикады и сражаться на них. По его плану, свергнуть существующий порядок должна была либерально-демократическая буржуазия, а коммунистический ЦК должен был возглавить процесс социальных преобразований, вернувшись из изгнания и направив «сознательных рабочих» террористически против демократических сил [13]. Тем не менее, амбиции лично возглавить процесс социальных преобразований у К. Маркса и Ф. Энгельса в какой-то момент закончились, о чем и говорит их возврат к идее кооперативного пути перехода к коммунизму.

\section{Библиографический список}

1. Будович Ю.И. Кооперативы как альтернативная «нефинансовая» система ресурсообеспечения // Экономические науки. 2020. № 11 (192). С. 231-240.

2. Будович Ю.И. Научно-технический прогресс как фактор неэффективности бюджетных расходов // Экономические науки. 2020. № 3 (184). С. 7-12. 
3. Будович Ю.И., Лебедев К. Н. Место финансов в современной экономике (Экономика без финансов).- Краснодар: НИИ экономики ЮФО, 2020. 187 с.

4. Вурмбранд Р. Маркс и сатана: Голос мучеников. 139 с.

5. Дьяченко В.И. Марксизм о первой (начальной) фазе коммунизма / Инициативная группа по формированию движения За Коммунистическое развитие в XXI веке. Из царства необходимости - в царство свободы. 05.02.2016 // http://communism21.org/abc/16 (дата обращения: 24.09.2020).

6. История экономики. Революционные демократы / Библиотекарь.Ру // http://www.bibliotekar.ru/2-839-istoriya-economiki-2/44.htm (дата обращения: 05.12.2020).

7. Кабе, Этьен / Википедия. Свободная энциклопедия // https://ru.wikipedia.org/wiki/\%D0\%9A\%D0\%B0\%D0\%B 1\%D0\%B5,_\%D0\%AD\%D1\%82\%D1\%8C\%D0\%B5\%D0\%BD (дата обращения: 05.12.2020).

8. Карамурза С. Предисловие к книге Ж. Аттали «Карл Маркс» / livejournal. 08.06.2018 // https://sg-karamurza. livejournal.com/300342.html (дата обращения: 10.10.2020).

9. Карл Маркс, Фридрих Энгельс. Полное собрание сочинений. Том сорок второй // https://www.marxists.org/ russkij/marx/cw/ (дата обращения: 04.12.2020).

10. Ключник Р. Террористическая война в России 1878-1881 гг. ГЛАВА ДЕСЯТАЯ. Революционная практика и предательство Маркса / ВикиЧтение // https://history.wikireading.ru/230118 (дата обращения: 05.10.2020).

11. Лебедев К.Н. «Финансовый» характер собственности на средства производства в СССР и кризис советской экономики // Экономические науки. 2020. № 11 (192). С. 250-259.

12. Лебедев К. Н. Экономика без финансов // Вопросы экономики и права. 2018. № 6 (120). С. 45-53.

13. Майбурд Е. Из заброшенной рукописи о Карле Марксе / ЛитБук // https://litbook.ru/article/1072/ (дата обращения: 14.10.2020).

14. Маркс, Карл / Википедия. Свободная энциклопедия // https://ru.wikipedia.org/wiki/\%D0\%9C\%D0\%B0\%D1\%8 0\%D0\%BA\%D1\%81,_\%0\%9A\%D0\%B0\%D1\%80\%D0\%BB (дата обращения: 05.12.2020).

15. Маркс К., Энгельс Ф. Сочинения. Издание второе. Том 4.- М.: Государственное издательство политической литературы, 1955. 616 (XIV).

16. Первые кооперативы - зарождение производственных кооперативов / Кооперативы против бедности. 24.05.2013 // https://pravo-wmeste.ru/pervye-kooperativy-zarozhdenie-proizvodstvennyx-kooperativov.html (дата обращения: 09.10.2020).

17. Первые кооперативы - история зарождения / Кооперативы против бедности. 22.05.2013 // https://pravowmeste.ru/pervye-kooperativy-istoriya-zarozhdeniya.html https://pravo-wmeste.ru/pervye-kooperativyistoriya-zarozhdeniya.html (дата обращения: 30.072020).

18. Пребывание в Париже: Маркс-социалист / Scibook.net // https://scibook.net/istoriya-sotsiologii-kniga/ prebyivanie-parije-marks-31786.html (дата обращения: 05.12.2020).

19. Собакин-Фисташков А. Собственность это кража / Проза.py // https://proza.ru/2020/05/05/2070 (дата обращения: 24.12.2020).

20. Собрание сочинений, том 27 (4 стр.) / Философия / Карл Маркс // https://mir-knig.com/read_418819-4 (дата обращения: 05.10.2020).

21. Фабзавкомы - рабочая демократия в действии/ВРАГКАПИТАЛА//https://1917.com/History/HRR/1082643581. html (дата обращения: 06.10.2020).

22. Энгельс Ф. К истории Союза коммунистов / AGITCLUB.ru // http://www.agitclub.ru/front/mar/bund2.htm (дата обращения: 06.10.2020).

23. Энгельс, Фридрих / Википедия. Свободная энциклопедия // https://ru.wikipedia.org/wiki/\%D0\%AD\%D0\%B D\%D0\%B3\%D0\%B5\%D0\%BB\%D1\%8C\%D1\%81,_DD0A4\%D1\%80\%D0\%B8\%D0\%B4\%D1\%80\%D0\%B8\%D1\%85 (дата обращения: 04.12.2020).

24. Юровская Е.Е. Брюссельская демократическая ассоциация. БСЭ / ВикиЧтение / https://info.wikireading.ru/ h8Gt6VLeSk (дата обращения: 09.10.2020). 